\title{
Minimally invasive deformity correction: surgical technique
}

\author{
Kevin S. Chen, M.D., Khoi D. Than, M.D., Frank LaMarca, M.D., and Paul Park, M.D. \\ Department of Neurosurgery, University of Michigan, Ann Arbor, Michigan
}

\begin{abstract}
This video details a minimally invasive treatment of symptomatic adult kyphoscoliosis. Both anterior and posterior approaches are used to obtain sagittal and coronal balance. In addition, improved lumbar lordosis is achieved to closely match the patient's pelvic incidence. The key steps for the lateral transpsoas procedure are detailed in the first portion of the video and include positioning, fluoroscopic localization, exposure with tubular retractor placement, interbody preparation and grafting, and closure. The second portion of the video shows positioning, fluoroscopic positioning/guidance, exposure for percutaneous pedicle screw placement, rod insertion, and closure.

The video can be found here: http://youtu.be/cHkTMtSXZ8A.
\end{abstract}

(http://thejns.org/doi/abs/10.3171/2013.V2.FOCUS13189)

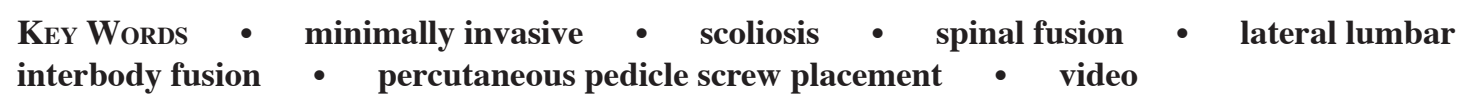

Manuscript submitted April 25, 2013

Accepted May 30, 2013.

Please include this information when citing this paper: DOI: 10.3171/2013.V2.FOCUS13189.

Address correspondence to: Paul Park, M.D., Department of Neurosurgery, University of Michigan, 1500 E. Medical Center Drive, Room 3552 TC, Ann Arbor, MI 48109-5338. email: ppark@ umich.edu. 